\title{
Correction to: Material scarcity and scalar justice
}

\author{
Matthew Adams ${ }^{1}$ (D) ${\text { Ross } \text { Mittiga }^{2} \text { (iD }}$
}

\section{Correction to: Philos Stud https://doi.org/10.1007/s11098-020-01539-3}

In the original version of the article, the Acknowledgements section was not included. The section is as follows:

Acknowledgements Earlier versions of this article were presented at a Stanford ethics postdoc workshop, a Stanford bioethics workshop, and the 2017 Western Political Science Association Conference. We thank the attendees, co-panelists, and discussants for their valuable feedback on those occasions. We are also grateful to Eamonn Callan, Hannah Carnegy-Arbuthnott, Jorah Dannenberg, Johannes Himmelreich, Laura Gillespie, George Klosko, David Magnus, Anne Newman, Fay Niker, and two anonymous referees for their many helpful comments.

Publisher's Note Springer Nature remains neutral with regard to jurisdictional claims in published maps and institutional affiliations.

The original article can be found online at https://doi.org/10.1007/s11098-020-01539-3.

Ross Mittiga

ross.mittiga@uc.cl

Matthew Adams

mra10@iu.edu

1 Department of Philosophy, Indiana University Bloomington, Sycamore Hall 026, 1033 E. 3rd St, Bloomington, IN 47405, USA

2 Instituto de Ciencia Política, Pontificia Universidad Católica de Chile, Av. Vicuña Mackenna 4860, Macul, Santiago, RM 7820436, Chile 